\title{
Advanced method for source term estimation and status of its integration in JRODOS
}

\author{
I. Kovalets ${ }^{1}$, S. Andronopoulos ${ }^{2}$, R. Hofman ${ }^{3}$, P. Seibert ${ }^{3}$ and I. Ievdin ${ }^{4}$ \\ ${ }^{1}$ Ukranian Centre for Environmental and Water Projects, prosp. Glushkova, 42, Kiev, Ukraine. \\ 2 NCSR Demokritos, Institute of Nuclear and Radiological Sciences and Technology, Energy and Safety, Aghia Paraskevi, Attiki, Greece. \\ ${ }^{3}$ University of Vienna, Althanstr. 14, 1090 Vienna, Austria. \\ ${ }^{4}$ Institute of Mathematical Machines \& Systems Problems NAS of Ukraine, prosp. Glushkova, 42, Kiev, Ukraine.
}

\begin{abstract}
In this work we present an automated source inversion algorithm suitable for usage in the real-time online emergency response system JRODOS in which measurements of gamma dose rates and other quantities taken at a wide range of distances from the Nuclear Power Plant are used to provide estimates of the time-dependent emission rates of different nuclides.
\end{abstract}

Keywords: source inversion / inverse problem / data assimilation / nuclear emergency / RODOS

\section{Introduction}

It is well known that during the emergency phase of a nuclear accident the most significant source of uncertainty is in source properties, such as released inventory, time distribution of release rate, and release height. In the 'bottom-up' algorithms, source terms are calculated using information about the processes inside the reactor leading to the release to environment. The resulting source terms such as those described in Landman (2007) are characterized by very high uncertainty. In the 'top-down' (or 'source inversion') algorithms, the source term is estimated by adjusting the solution of atmospheric dispersion model to measurements. The inverse problem is regularized using prior estimations of the source term typically taken from 'bottom-up' algorithms. Source inversion algorithms have been successfully applied for nuclear accidents (e.g. Winiarek et al., 2011; Saunier et al., 2013). However, the automation and usage of such algorithms in real-time is still at its preliminary stage. Winiarek et al. (2011) developed automated algorithms for near-real-time source estimation of radioactive release based on the data of the network of concentration measurements in France. However, the most reliably available measurements in the vicinity of nuclear power plants are gamma-dose rates (GDR). Saunier et al. (2013) presented a solution for the problem of source inversion using GDR measurements for the Fukushima accident, prescribing possible ranges of nuclide ratios. The aim of the present work was to develop an automated source inversion algorithm using GDR and other measurements taken at a wide range of distances from the NPP to establish the timedependent release rates of different nuclides at unknown height, suitable for use in real-time online decision support systems. The status of implementation of the algorithm in the European nuclear emergency response system JRODOS
(Ievdin et al., 2010) is described and discussed. The detailed description of the source inversion algorithm, its integration in JRODOS system and results of its verification is available in Kovalets et al. (2016).

\section{Source inversion method and its integration in JRODOS}

We treat source inversion as a variational problem in which the cost function characterizing the difference of simulated results and measurements is minimized with respect to timeand height-dependent release rates of different nuclides. The source receptor matrix (SRM) characterizing sensitivity of calculated values (air concentrations, deposition, GDR) at points of measurements to values of nuclides emission rates is calculated during a forward run of atmospheric dispersion model DIPCOT (Andronopoulos et al., 2010; Tsiouri et al., 2012). Prior information about source term is used to regularize the inversion problem and to assure uniqueness of the solution. The issue of unknown nuclide composition of the release is handled using the newly proposed approach of augmenting the SRM and measurement vector with relationships characterizing the ratios of release rates of different nuclides. The parameters of the regression problem include error variances of the first-guess source term, error variances of observations, of simulated results and of nuclide ratios used in augmented minimization problem. Parameterizations for the above-mentioned error variances are proposed based on literature review and physical considerations. The developed method is integrated in the Source Inversion Module (SIM) of the JRODOS system. The graphical user interface allows the user to set basic steering and model parameters of SIM and to export the estimated source term for subsequent usage by the JRODOS Local Scale Model Chain (LSMC). 


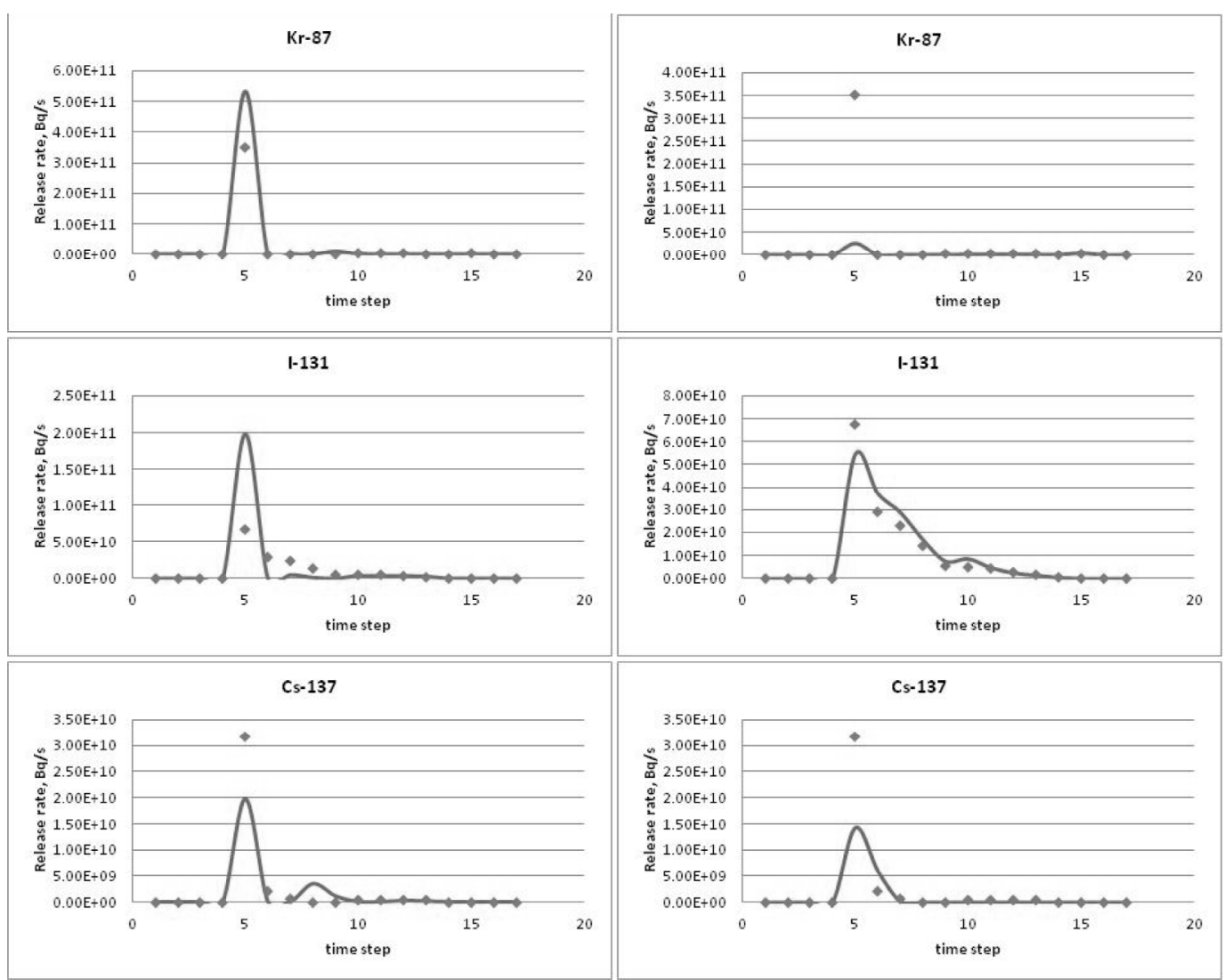

Figure 1. Time series of true (dots) and estimated (line) release rates for selected nuclides for the case of a first guess source function shifted backward in time by $2 \mathrm{~h}$ and increased (left) or decreased (right) by a factor of 10 as compared to the true source function

\section{Results of calculations}

The source inversion method has been tested for a hypothetical release scenario (source term Muehleberg-1 from Seibert et al., 2013) and the meteorological conditions of the ETEX experiment (Gryning et al., 1998). The source term consisted of 21 nuclides and was characterized by two release phases of 0.5 and $4 \mathrm{~h}$, separated by $2 \mathrm{~h}$ of no release before the beginning and after the end of each release phase. The SRM and the vector of 'measurements' (GDRs at the locations of the ETEX network sites with 10 min time resolution) were generated by different runs of DIPCOT which has a stochastic component and thus these runs were slightly different (by about 5\%). The results of the source inversion with automatically assigned values of regularization parameters are presented in Figure 1 for selected nuclides representative of each group (noble gases, iodine and aerosols). In all cases the time of maximum release rate is correctly found and estimated release rates are satisfactory. The release height (equal to $50 \mathrm{~m}$ ) was correctly estimated by performing source inversions with different release heights and choosing the run with minimum achieved value of cost function.

\section{Conclusions}

We have presented an automated source inversion algorithm suitable for usage in real-time online emergency response systems in which measurements of gamma dose rate and other quantities taken at a wide range of distances from the NPP are used to derive the time-dependent release rate of different nuclides. The algorithm is integrated into the European nuclear emergency response system JRODOS. The robustness and real-time applicability of the developed algorithm were demonstrated. Further testing of the algorithm with real measured data is planned. It is recommended to combine the algorithm with the meteorological data assimilation tools (Kovalets et al., 2004) previously developed and implemented within the JRODOS system. Further work may also include the development of more sophisticated though still practical algorithms for better estimation of the various error variances. A full implementation of the algorithm within the JRODOS system will also require adaptation of the existing measurement databases.

Acknowledgment. The research leading to these results has received funding from the European Atomic Energy Community Seventh Framework Programme FP7/2012-2013 under grant agreement 323287.

\section{References}

Andronopoulos S., Davakis E., Bartzis J.G., Kovalets I.V. (2010) RODOS meteorological pre-processor and atmospheric dispersion model DIPCOT: a model suite for radionuclides dispersion in complex terrain, Radioprotection 45, S77-S84.

Gryning S.E. et al. (1998) Meteorological conditions at the release site during the two tracer experiments, Atmos. Environ. 32, 4213-4137. 
Ievdin Y., Trybushny D., Zheleznyak M., Raskob W. (2010) RODOS re-engineering: aims and implementation details, Radioprotection 45, S181-S190.

Kovalets I., Andronopoulos S., Bartzis J., Gounaris N., Kushchan A. (2004) Introduction of data assimilation procedures in the meteoroloical pre-processor of atmospheric dispersion models used in emergency response systems, Atmos. Environ. 38 (3), 457 467.

Kovalets I., Hofman R., Seibert P., Andronopoulos S., Ievdin I. (2016) Description of software module for source term estimation using advanced method integrated in DSS RODOS, Report of the EC FP7 PREPARE project PREPARE(WP4)-(16)-04. Available at: 10.13140/RG.2.1.5169. 1285.

Landman C. (2007) Scenario data sets and scenarios for RODOS PV6 final, Report RODOS(RA7)-TN(04)-02, Karlsruhe Institute of Technology, 49 pp.
Saunier O., Mathieu A., Didier D., Tombette M., Quélo D., Winiarek V., Bocquet M. (2013) An inverse modeling method to assess the source term of the Fukushima nuclear power plant accident using gamma dose rate observations, Atmos. Chem. Phys. 13, 11403-11421.

Seibert P., Arnold D., Arnold N., Gufler K., Kromp-Kolb H., Mraz G., Sholly S., Wenisch A. (2013) Flexrisk-Flexible tools for assessment of nuclear risk in Europe. BOKU-Met Report 23. Available at http://www.boku.ac.at/met/report/BOKU-Met_Re port_23_PRELIMv2_online.pdf.

Tsiouri V., Kovalets I., Andronopoulos S., Bartzis J.G. (2012) Source function estimation with data assimilation of gamma dose measurements in Lagrangian atmospheric dispersion model DIPCOT, Radiat. Prot. Dosim. 148, 34-44.

Winiarek V., Vira J., Bocquet M., Sofiev M., Saunier O. (2011) Towards the operational estimation of a radiological plume using data assimilation after a radiological accidental atmospheric release, Atmos. Environ. 45, 2944-2955.

Cite this article as: I. Kovalets, S. Andronopoulos, R. Hofman, P. Seibert, I. Ievdin. Advanced method for source term estimation and status of its integration in JRODOS. Radioprotection 51(HS2), S121-S123 (2016). 